\title{
Design, Fabrication and Testing of Fixture for Implementation of a New Approach to Incorporate Tool tilting in Friction Stir Welding
}

\author{
Mokhtar Awang ${ }^{1, a}$, Sajjad Raza Khan ${ }^{1}$, Bilal Ghazanfar ${ }^{1}$, and Fadhil Abdul Latif ${ }^{1}$ \\ ${ }^{1}$ Mechanical Engineering Department, Universiti Teknologi PETRONAS, 31750 Seri Iskandar, Perak
}

\begin{abstract}
Friction Stir Welding (FSW) is solid-state process for joining materials by using frictional heat generated due to rotating tool along the weld line. Since its invention about two decades ago, wide spread use of FSW is still restricted due to very expensive purpose built FSW machines available in the market. As an alternative, a milling machine can be used to carry out the FSW depending on the capabilities of the machine. In cases where milling machines have a fixed head, limitation of zero degree tool tilt angle results in substantial defects (e.g. tunnel defect) in weldments. The objective of this study is to design and fabricate an adjustable-angle fixture to incorporate tool tilting in a $\mathrm{CNC}$ milling machine with fixed spindle head. The testing of the fabricated fixture is then carried out by running the FSW experiments at different tilt angles.
\end{abstract}

\section{Introduction}

The FSW process is solid-state process, invented at The Welding Institute (TWI) in United Kingdom (UK), which involves joint formation below the base material's melting temperature. The heat generated in the joint area is typically about $80-90 \%$ of the melting temperature $[1,2]$. In FSW, a cylindrical shouldered tool with a profiled pin is rotated and plunged into the joint area between two pieces of sheet or plate material as shown in Fig. 1. The parts have to be securely clamped to prevent the joint faces from being forced apart. Frictional heat between the wear resistant welding tool and the work pieces causes the latter to soften without reaching melting point, allowing the tool to traverse along the weld line.

One of the major obstacles to broader industrial implementation of FSW has been the affordability and suitability of FSW machines. The actual FSW machine can reach the price around one million US dollar [3]. This is not favourable for the small industries, university laboratory or any personnel to invest this amount of money for expensive FWS machine.

Fortunately, Milling machines owing to their rotating tool and traversing ability can be utilized to carry out FSW operations. Use of milling machines is previously reported in literature[4]. But, in cases where milling machines have a fixed head, limitation of zero degree tool tilt angle results in substantial defects (e.g. tunnel defect) in weldments. The importance of the tool tilting angle is well established. Many researchers have reported the effect of tool tilting angle and optimum tool tilting angle for their studies[3].

\footnotetext{
${ }^{a}$ Corresponding author: mokhtar_awang@petronas.com.my
}

This is an Open Access article distributed under the terms of the Creative Commons Attribution License 2.0, which permits unrestricted use, distribution, and reproduction in any medium, provided the original work is properly cited. 


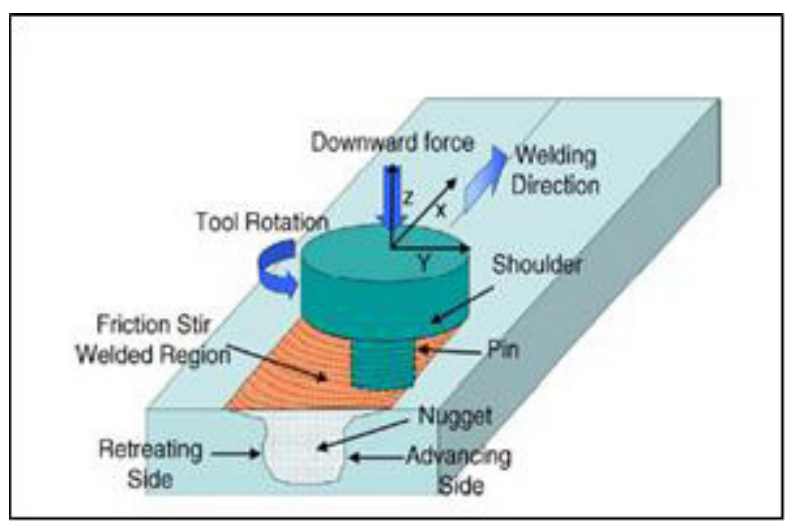

Figure 1. Basic Principle of FSW [3]

Smith et al [5] have developed a model using tool tilting angle and gap between the joining plates to predict the joint efficiencies. Current work presents and discusses different fixture designs to utilize the tool tilting approach suggested by Bilal et al [6] for such above mentioned cases e.g. Bridgeport VMC2216. These designs are then evaluated against a given criteria and best design is then selected and adopted.

\section{Fixture Designing and Evaluation}

Fixtures have an important role to play in FSW by stopping the joining material from going apart in plunging phase. Bhagel et al [7] reported the designing and development of fixture for FSW. But this design is not to incorporate tool tilting. In order to design fixture for our need a few ideas were generated and the best design that can suit the objective of creating adjustable angle features is selected based on the highest score from Pugh Method evaluation. The method is evaluated based on several criteria which will define its suitability for the overall project, as summarized in the Table 1.

Table 1. Design Criteria

\begin{tabular}{|l|l|}
\hline Criteria & Description \\
\hline $\begin{array}{l}\text { Design } \\
\text { Complexity }\end{array}$ & $\begin{array}{l}\text { Number of different components, mechanism size, number of non-symmetry } \\
\text { and complex shape. }\end{array}$ \\
\hline Functionality & The range of adjustable angle it can provide \\
\hline Practicality & $\begin{array}{l}\text { Ease to be operated and used by end user, time taken for preparing the fixture } \\
\text { before proceeding to FSW process }\end{array}$ \\
\hline Strength & $\begin{array}{l}\text { Maximum downward force of the machine spindle it can sustain during the } \\
\text { FSW. (specified to min force requires for aluminum welding ) }\end{array}$ \\
\hline $\begin{array}{l}\text { Procurement of } \\
\text { material/ } \\
\text { components }\end{array}$ & $\begin{array}{l}\text { Expected price of the components and its availability in the market to be } \\
\text { bought at small package. }\end{array}$ \\
\hline Workmanship & $\begin{array}{l}\text { The capability of the local machine, size, dimensioning tolerance, and level of } \\
\text { accuracy needed during the fabrication process }\end{array}$ \\
\hline
\end{tabular}

Upon concept selection and drafting, the chosen concept is roughly designed with its important features that will serve certain functionality. Fig. 2 and Fig. 3 show every part included into final design with description of their individual function as listed in Table 2.

This adjustable-angle fixture works by converting rotational motion of the threaded bolt into translational of the wedge. The wedge then will travel along the designated track and lift up the top fixture at different height, resulting different tilting angle at every increment. In short, it works based on trigonometry principle where varying the length of adjacent side will alter the resulted degree of triangle. 


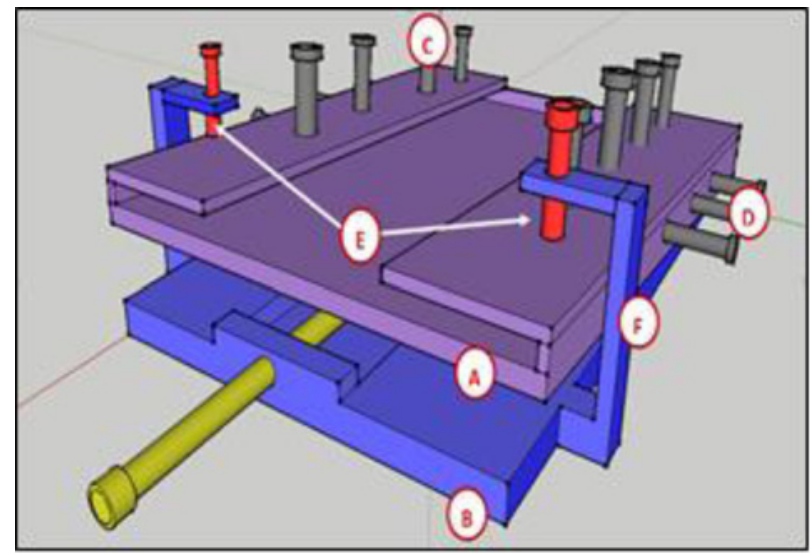

Figure 2. Draft of the fixture design at view 1

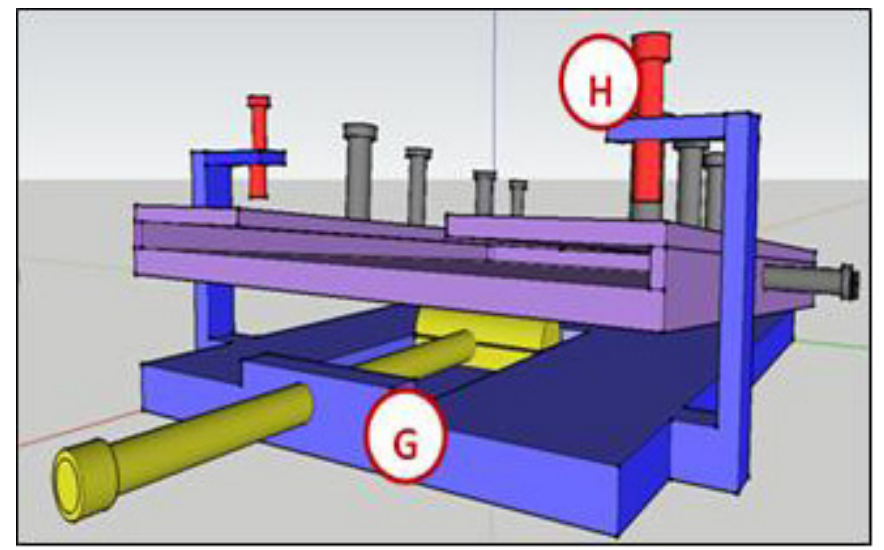

Figure 3. Draft of the fixture design at view 2

Table 2. List of Parts and Their Features used in the Fixture

\begin{tabular}{|c|c|c|}
\hline Label & Part & Features \\
\hline $\mathbf{A}$ & Top Jig & Interface to hold the work pieces during the FSW process \\
\hline $\mathbf{B}$ & Base & $\begin{array}{l}\text { Lower part of the jig that provide the designated slot for } \\
\text { adjustable wedge }\end{array}$ \\
\hline $\mathbf{C}$ & $\begin{array}{l}\text { Top Bolt } \\
\text { and Nut }\end{array}$ & Adjust, tighten and restrict the thickness of the work pieces used \\
\hline $\mathbf{D}$ & $\begin{array}{l}\text { Side Bolt } \\
\text { and Nut }\end{array}$ & Adjust, tighten and restrict the width of the work pieces used \\
\hline $\mathbf{E}$ & Clamping & $\begin{array}{l}\text { Multi-angle bolt to clamp the top bunk at fixed inclination during } \\
\text { FSW process }\end{array}$ \\
\hline $\mathbf{F}$ & $\begin{array}{l}\text { Clamping } \\
\text { holder }\end{array}$ & Part of the base that provide the holder for clamping bolt \\
\hline $\mathbf{G}$ & $\begin{array}{l}\text { Adjustable } \\
\text { wedge }\end{array}$ & $\begin{array}{l}\text { Assembly of bolt and wedge that can vary the position of wedge } \\
\text { when the bolt is screwed in or out. }\end{array}$ \\
\hline
\end{tabular}




\subsection{Fabrication of Fixture}

After finalizing the drawing details and product design features, all main parts were fabricated at small dimensional tolerance. They were fabricated individually before assembled together by using bolts and fasteners. The final product is shown in the Fig. 4.

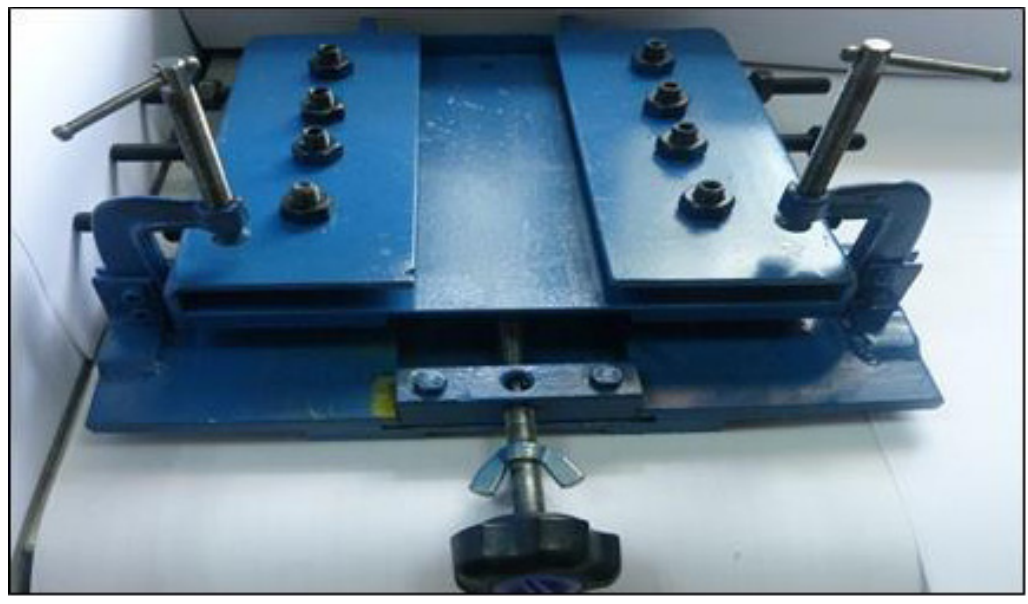

Figure 4. Final product of FSW adjustable-angle fixture

\subsection{Testing of Fixture}

The fabricated adjustable fixture of CNC milling machine was tested for its stability and reliability, by operating it at various tilt angle during the real FSW process. Other important parameters such as tool rotational speed and traverse speed are set up at optimum condition, and maintain fixed throughout the experiment. Table 3 summarizes the experiment set up for this FSW experiment, and Fig. 5 shows the Adjustable-Angle fixture was being tested during FSW process.

Material used in this experiment was aluminum alloy 6061, where it was perpendicularly cross sectioned as shown in Fig. 6 after the FSW process in order to examine the quality of the welded joint

Table 3. Experimental Setup

\begin{tabular}{|c|c|c|}
\hline $\begin{array}{c}\mathbf{E x} \\
\text { p. }\end{array}$ & $\begin{array}{l}\text { Tilting } \\
\text { Angle } \\
\left({ }^{\circ}\right)\end{array}$ & Experiment Setup \\
\hline $\begin{array}{c}\text { Set } \\
1\end{array}$ & $\mathbf{0}$ & $\begin{array}{l}\text { Process Parameter } \\
\text { Tool Rotational Speed : } 1200 \mathrm{rpm} \\
\text { Transverse Speed }: 50 \text { Plunging Feed rate }: 100 \mathrm{~mm} / \mathrm{s}\end{array}$ \\
\hline $\begin{array}{c}\text { Set } \\
2\end{array}$ & 2.5 & $\begin{array}{l}\text { Dwell Time (plunging) : } 20 \mathrm{sec} \text { Dwell Time (withdrawn) }: 4 \mathrm{sec} \\
\text { Welding Length: } 70 \mathrm{~mm} \text {, Weld type : Butt joint } \\
\text { Material }\end{array}$ \\
\hline $\begin{array}{c}\text { Set } \\
3\end{array}$ & 3.5 & $\begin{array}{l}\text { Dimension : } 100 \mathrm{~mm} \times 100 \mathrm{~mm} \times 10 \mathrm{~mm} \\
\text { Tool } \\
\text { Profile : Taper }\end{array}$ \\
\hline $\begin{array}{c}\text { Set } \\
4\end{array}$ & 5.0 & $\begin{array}{l}\text { Pin Length (b) : } 8 \mathrm{~mm} \\
\text { Max Pin Diameter (d) }: 8.7 \mathrm{~mm} \\
\text { Min Pin Diameter (c): } 5.4 \mathrm{~mm}\end{array}$ \\
\hline
\end{tabular}




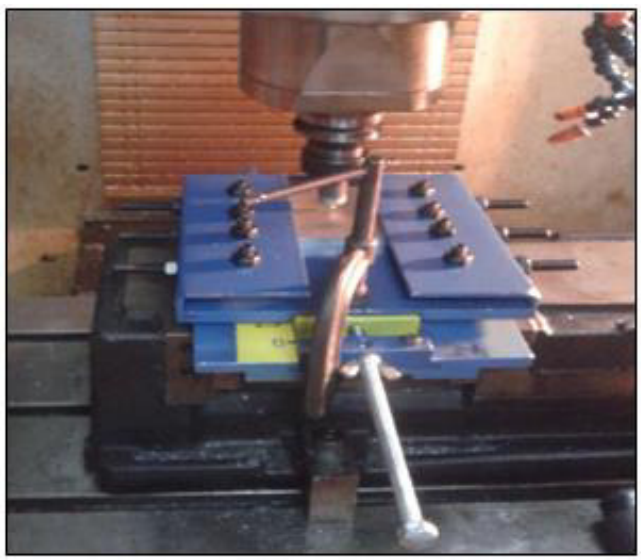

(a)

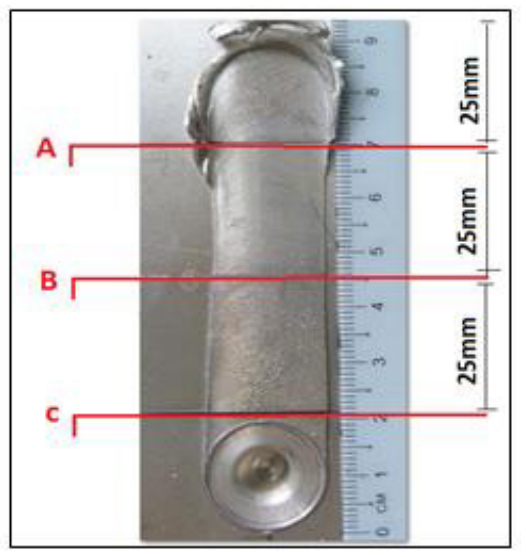

(b)

Figure 5. (a) Adjustable-angle fixture was being tested for FSW (b) Welded joint is cross sectioned based on specific dimension

Table 4. Product Specification Label

\begin{tabular}{|l|l|}
\hline Name & Adjustable-Angle Fixture of Friction Stir Welding (FSW) \\
\hline Application & BridgeportVertical Milling centre 2216 \\
\hline Dimension & $360 \mathrm{~mm} \times 300 \mathrm{~mm}$ x $150 \mathrm{~mm}$ \\
\hline Weight & $14 \mathrm{~kg}$ \\
\hline Color & Blue \\
\hline Material & Mild Steel \\
\hline $\begin{array}{l}\text { Max Tested } \\
\text { Downward Force }\end{array}$ & $6.0 \mathrm{kN}$ \\
\hline Tilting Angle & Minimum : $0^{0}$ Maximum : $5^{0}$ \\
\hline $\begin{array}{l}\text { Work pieces } \\
\text { Dimension } \\
\text { (per piece) }\end{array}$ & $\begin{array}{l}\text { Maximum width : } 110 \mathrm{~mm}, \text { Minimum width : 70 mm, } \\
\text { Maximum Length : } 210 \mathrm{~mm}, \text { Minimum Length : 55mm, },\end{array}$ \\
\hline $\begin{array}{l}\text { Cost } \\
\text { Material cost: USD100, Fabrication Cost: USD72, Total } \\
\text { Cost: USD172 }\end{array}$ \\
\hline
\end{tabular}

\section{Results and Discussion}

Final product of Adjustable Angle Fixture has been tested and proven to successfully incorporate the tool tilting in CNC Bridgeport VMC2216 machine for actual FSW application. Figure 4 shows the prototype with its detail specification listed in Table 4. It possesses the strength to sustain downward load acted by the spindle force against its structure, while the working adjustable wedge mechanism is properly functioning as designed. It can provide steady clamping force to hold the work pieces and the observation on welded joint shows equally comparable quality to actual FSW machine application.

The advantage of utilizing the existing CNC machine by adopting the application of AdjustableAngle Fixture for FSW process can be justified economically, where it is more affordable compared to purchasing an actual FSW machine. Comparing this product to previous fixtures, it demonstrates better advantages in few aspects which is :

a) Accommodate wider range tilting angle and dimension

b) Reduce FSW process preparation time 


\section{Conclusion}

In conclusion, the final product of Adjustable-Angle Fixture demonstrates great potential to fully utilize the existing CNC Bridgeport VMC2216 machine for FSW, resulting into quality welds comparable to welds produced by actual FSW machine.

\section{Acknowledgement}

The financial support and laboratory facilities utilization of the Universiti Teknologi PETRONAS (UTP) is gratefully acknowledged.

\section{References}

1. Friction Stir Welding Technical Handbook. (2010), LAXÅ, Sweden: ESAB AB. 27.

2. Wayne M. Thomas, E.D.N., James C. Needham, Michael G. Murch, Peter Temple-Smith, Christopher J. Dawes. (1995). US Patent 5, 460, 317.

3. Mishra, R.S. and Z.Y. Ma, Friction stir welding and processing. Materials Science and Engineering: R: Reports, (2005). 50(1-2), 1-78.

4. Badheka, V.J., Utilisation of a Conventional Milling Machine for Friction Stir Welding of Commercial Aluminum. Welding Research Abroad, (2010). 56(6), 6.

5. Smith, C.B., et al., Effect of Compliance and Travel Angle on Friction Stir Welding With Gaps. Journal of Manufacturing Science and Engineering, (2010). 132(4), 041010-041010.

6. Bilal Ghazanfar, Mokhtar Awang, Sajjad Raza Khan, Hasan Fawad, Advanced Materials Research, (2013). 701, 378-381.

7. Baghel, P.K., Design and development of fixture for friction stir welding. Innovative System Design and Engineering, (2012). 3(12), 40-47. 